\title{
Investigation of Nickel Phthalocyanine Thin Films for Solar Cell Applications
}

\author{
Eman M. Nasir, Mohammed T. Hussein, Addnan H. Al-Aarajiy \\ Department of Physics, College of Science, University of Baghdad, Baghdad, Iraq \\ Email: eman.itabi@gmail.com
}

How to cite this paper: Nasir, E.M., Hussein, M.T. and Al-Aarajiy, A.H. (2019) Investigation of Nickel Phthalocyanine Thin Films for Solar Cell Applications. Advances in Materials Physics and Chemistry, 9, 158-173.

https://doi.org/10.4236/ampc.2019.98013

Received: July 31, 2019

Accepted: August 27, 2019

Published: August 30, 2019

Copyright $\odot 2019$ by author(s) and Scientific Research Publishing Inc. This work is licensed under the Creative Commons Attribution International License (CC BY 4.0).

http://creativecommons.org/licenses/by/4.0/

\begin{abstract}
Ni-Phthalocyanine thin films were thermally evaporated with different substrate temperatures $(300-450) \mathrm{K}$ on (silicon wafer, glass) substrates. The chemical bonds of NiPc powder were investigated by FTIR spectrum, which introduce good information for NiPc bonds and their locations. The optical properties have been studied by UV-Visible, and Photoluminescence (PL) Spectra. The NiPc thin films have direct gap for all samples. The values of energy gap which is calculated by PL spectra are lower than those calculated by Tauc equation. It is found there are three activation energies, the mobility and concentration of carriers have been measured and, the NiPc films are p-type. $\mathrm{P}-\mathrm{NiPc} / \mathrm{n}-\mathrm{Si} \mathrm{HJ}$ solar cell was fabricated at substrates temperatures $(300,400) \mathrm{K}$. From I-V and C-V characteristic, abrupt junction has been found, photovoltaic characteristics have been observed with Voc of (0.335 $0.415) \mathrm{V}$, and Isc of $(2.77-4.26) \mu \mathrm{A}$, and the efficiency of $(3.08-5.03) \%$ at room temperature and substrate temperature $(300,400 \mathrm{~K})$ and under illumination of $55 \mathrm{~mW} / \mathrm{cm}^{2}$ using Halogen lamp. Ideality factors of the junction increase from (0.61 - 0.73) and barrier height increases from $2.53 \mathrm{eV}$ to $3.69 \mathrm{eV}$ while shunt resistance decreases from $3.76 \mathrm{~K} \Omega$ to $2.59 \mathrm{~K} \Omega$ and series resistance decreases slightly from $0.24 \mathrm{~K} \Omega$ to $0.23 \mathrm{~K} \Omega$. The fill factor decreases from 0.46 to 0.4 with the increase of substrate temperature.
\end{abstract}

\section{Keywords}

Nickel Phthalocyanine, Optical Property, Electrical Property, Photoluminescence, Solar, Cell

\section{Introduction}

Phthalocyanines are regarded as optical materials. The optical film properties analysis explains the identity of materials and the correlation between theoretical and experimental work [1]. Inorganic materials have attracted attention as novel 
material due to their chemical stability, low heat conduction, and diversity of optical properties and wide application in optoelectronic devices [2] [3]. Phthalocyanine can be considered as active materials in different light processes [4]. By discovering phthalocyanine since 1907, many studies on the optical properties have been achieved [5] [6]. There is a great interest in studying the electronic structure of phthalocyanine because of its high absorption in the visible region [7] [8] [9] [10]. Phthalocyanine happens in three phases $(\alpha, \beta, \gamma)$; the molecules are distributed in a parallel to each other leading to forming vertical structure in $\alpha$ phase and $\beta$ phase, and in $\alpha$-phase, phthalocyanine contains crystalline grain with $10 \mathrm{~nm}$ of diameter, whereas $\beta$ phase contains bigger crystalline grain and fiber optical structure and this phase is formed at higher temperature. Many methods have been used to prepare metal phthalocyanine films [11]. Most of the metals have been able to coordinate with the phthalocyanine. Metal phthalocyanine $(\mathrm{MPc})$ has great attractive as catalysts for organic chemical sensor and solar cell application due to simple prepared technique, low cost and stability for chemical and thermal properties [8]. NiPCs have $\alpha$-phase and monoclinic structure, with $\beta=123.46^{\circ}$ and lattice constant $\mathrm{a}=1.513 \mathrm{~nm}, \mathrm{~b}=0.462 \mathrm{~nm}, \mathrm{c}=2.03$ $\mathrm{nm}$ [9]. Organic semiconductor NiPCs contain single bond and double bonds [10]. The microscopic characteristic of the material can be known by studying optical measurements of film and this gives important information to build electronic devices [12]. The objectives of this work are the synthesis of thermally evaporated NiPc film using thermal evaporation technique, to study some of the properties at various $\mathrm{T}_{\mathrm{s}}$, also to prepare solar cell from $\mathrm{n}$-Nickel Phthalocyanine: p-Silicon $\mathrm{HJ}$ and to study their properties.

\section{Experimental}

NiPc thin films at different substrate $(300-450 \mathrm{~K})$ were prepared by thermal evaporation (Edwards 306 systems) on (glass, n-Silicon) by using NiPc powder obtained from Aldrich chemical company. NiPc thin films were grown with a thicknesses of $(50,110,265$ and 350) $\mathrm{nm}$ on glass and on Si wafer substrates at room temperature. Also NiPCs film was grown in $\mathrm{T}_{\mathrm{s}}(300,325,350,400,450) \mathrm{K}$ with a thickness $265 \mathrm{~nm}$, under vacuum pressure $10^{-5}$ torr.

Fourier-transformed Infra-red spectra for $\mathrm{NiPc}$ as a powder were measured by (Shimadzu FTIR spectrometer). The optical property of NiPc film was determined in the range $(200-1000) \mathrm{nm}$ by using UV/V is spectrometer. Photoluminescence was measured (Renishaw 2000) system, and at excitation wavelengths of $300 \mathrm{~nm}$. Electrical properties were measured, concentration and mobility of carrier and Hall effect of film were determined. NiPc/Si heterojunction has been fabricated as in Figure 1. Single crystal n-type Silicon wafer was used with phosphor doping, crystal orientation (100), thickness $380 \mu \mathrm{m}$ and electrical resistivity of 5 - $10 \Omega . \mathrm{cm}$. The wafer from VSM company, USA, Silicon wafer was cleaned using etching process by immersed $\mathrm{Si}$ wafer and stirrer them in a solution containing $3 \mathrm{ml} \mathrm{HNO}_{3}, 1 \mathrm{ml} \mathrm{HF}, 2 \mathrm{ml} \mathrm{H}_{2} \mathrm{O}$ for ( 1 - 3) minutes, then immersed in distilled water for several times. Finally, it was dried by blower and 
swab in special paper. I-V and $\mathrm{C}-\mathrm{V}(\mathrm{at} 1 \mathrm{kHz})$ characteristic in the case of darkness and light were achieved for the $\mathrm{NiPc} / \mathrm{Si} \mathrm{Hj}$ cell by digital Keithley, power supply and LRC meter. Solar cell properties and there parameters $\left(\beta, \varphi, \mathrm{V}_{\mathrm{oc}}, \mathrm{I}_{\mathrm{sc}}\right.$, $\mathrm{Im}, \mathrm{Vm}, \eta$ etc..) have been achieved at light to the $\mathrm{NiPc} / \mathrm{Si} \mathrm{HJ}$ with optimum thickness and substrate temperature at forward and reverse conditions with intensity $55 \mathrm{~mW} / \mathrm{cm}^{2}$ by using Halogen lamp type Philips of $120 \mathrm{~W}$.

\section{Results and Discussion}

The FT-IR spectra to NiPc as a material were recorded at RT, a comparison between these spectra of $\mathrm{NiPc}$ and $\mathrm{H}_{2} \mathrm{Pc}$ spectra as in Figure 2. It is observed in the range (400 - 2000) $\mathrm{cm}^{-1}$ bond bending whereas in the range $(2000-4000) \mathrm{cm}^{-1}$ the bond stretching. Weak peaks in the range $(600-400) \mathrm{cm}^{-1}$ which indicate the presence of (metal-Nitrogen) bond vibration at $(508-578) \mathrm{cm}^{-1}$ which assigned for (Nickel-Nitrogen). The band $\mathrm{C}-\mathrm{N}$ at $(1334-1320) 1 / \mathrm{cm}$ is, and the peak bond $\mathrm{C}=\mathrm{C}$ at $(1612) \mathrm{cm}^{-1}$ and the peak (1533) $\mathrm{cm}^{-1}$ represents Benzene ring band. The spectrum shows the absent of stretching band (N-H) which appears in $\left(\mathrm{H}_{2} \mathrm{Pc}\right)$ spectrum.

The incident light $\left(I_{o}\right)$ and transmission intensity $\left(I_{T}\right)$ is given by [12] [13]:

$$
I_{T}=I_{o} \mathrm{e}^{-\alpha t}
$$

The absorption coefficient $\alpha$ and $\mathrm{t}$ is thickness of films. The $\alpha$ of film was calculated by absorption and transmission spectra according to:

$$
\alpha=\ln T^{-1} / t
$$

$I_{T} / I_{o}$ is defined as the transmittance $(\mathrm{T})[1]$.

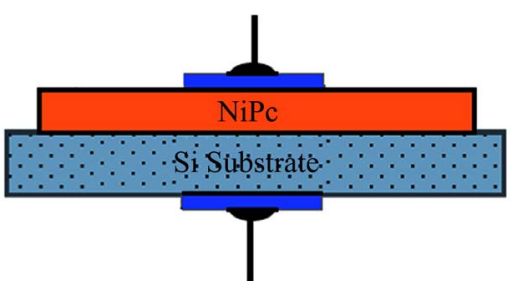

Figure 1. The NiPc/Si heterojunction diagram.

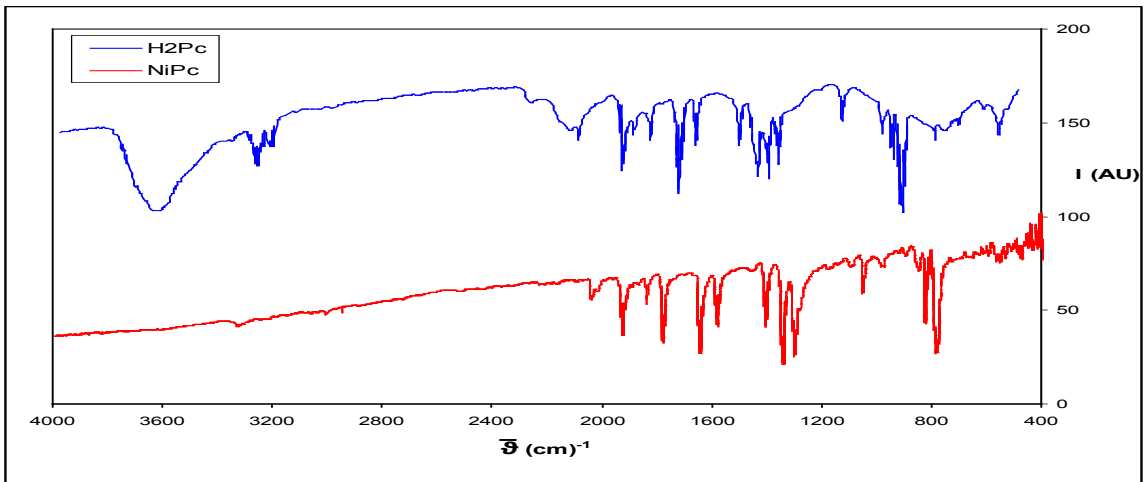

Figure 2. FT-IR spectra for NiPc and for H2Pc powders. 
Figure 3 represents the absorbance for Nickel phthalocyanine film at various $\mathrm{T}_{\mathrm{s}}$, it is observed substrate temperature increasing causes absorbance decreases, normally, except in the range (350 - 400) $\mathrm{K}$ where there is inverse behavior for $\mathrm{Q}$ band and $\mathrm{B}$ band, and the variations in $(\mathrm{Q})$ bands less than in $\mathrm{B}$ band and minor changes happens in flat area, this behavior because of a good crystal arrangement at high substrate temperatures. It is observed that band of absorption $B$ higher from band of absorption Q. Effect of substrate temperature on absorbance is shown in Figure 4. A red shift in $B, Q_{1}$ bands peak positions with substrate temperature increasing has been seen while no change in $Q_{2}$ peak position as shown in Table 1.
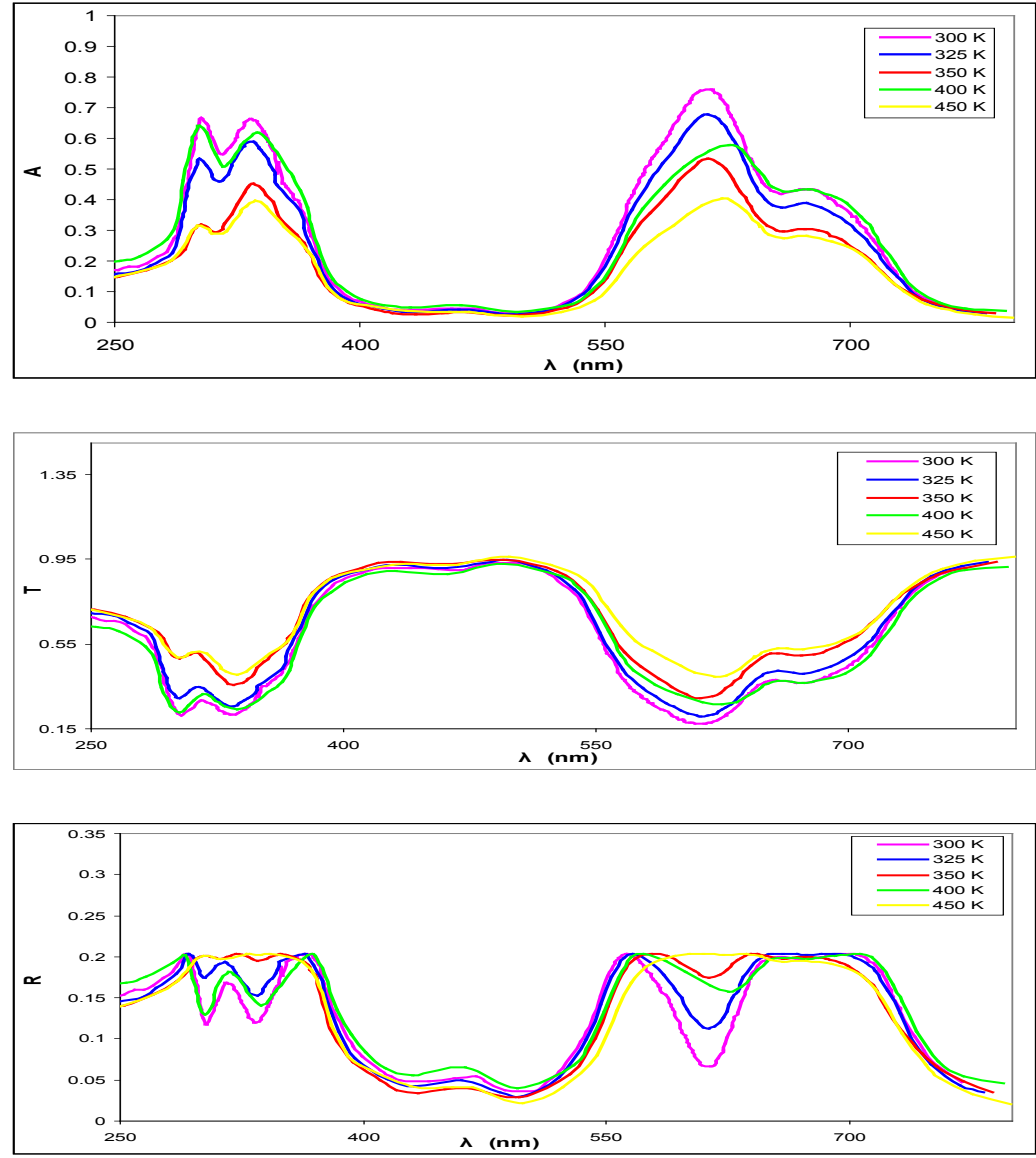

Figure 3. Absorbance, transmittance and reflectance versus $\lambda$ to Nickel phthalocyanine film at various $\mathrm{T}_{\mathrm{s}}$.
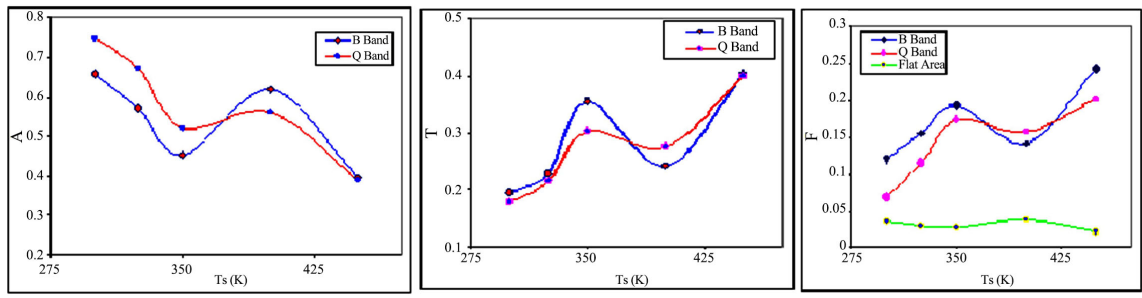

Figure 4. Absorbance, transmittance and reflectance versus $\mathrm{T}_{\mathrm{s}}$ for Nickel phthalocyanine film at various Ts. for B and Q bands. 
Table 1. Values of maximum absorption peak for NiPc thin films at different substrate temperatures.

\begin{tabular}{|c|c|c|c|}
\hline \multirow{2}{*}{$\begin{array}{c}\text { Substrate } \\
\text { Temperature } \\
\text { (K) }\end{array}$} & \multirow{2}{*}{$\begin{array}{c}\text { B band } \\
\text { peak } \\
\text { position } \\
(\mathrm{nm})\end{array}$} & \multicolumn{2}{|c|}{ Q-band } \\
\hline & & $\begin{array}{l}\mathrm{Q}_{1} \text { peak } \\
\text { position } \\
(\mathrm{nm})\end{array}$ & $\begin{array}{c}\mathrm{Q}_{2} \text { peak } \\
\text { position } \\
(\mathrm{nm})\end{array}$ \\
\hline 300 & 336 & 616 & 673 \\
\hline 325 & 336 & 617 & 673 \\
\hline 350 & 336 & 620 & 673 \\
\hline 400 & 335 & 625 & 673 \\
\hline 450 & 342 & 627 & 673 \\
\hline
\end{tabular}

Substrate temperature effect on transmittance was studied for NiPc thin films and shows that maximum transmittance was in the range (400 - 500) $\mathrm{nm}$ wavelength and clear variations happened in $\mathrm{B}$ and $\mathrm{Q}$ bands, while the small variations are in flat area. The transmittance spectra for NiPc film at various $\mathrm{T}_{s}$, are shown in Figure 3 and Table 1.

Effect of substrate temperature on transmittance has been studied, one can see the transmittance increases normally with substrate temperature increase, except in the range of $(350-400) \mathrm{K}$ where there is a reverse behaviour, and $\mathrm{Q}$ band variation in transmittance is smaller than that for $\mathrm{B}$ band for same values of $\mathrm{T}_{s}$ as shown in Figure 3 and Table 1.

The reflectance spectra for NiPc film at Ts $(300-450) \mathrm{K}$ have been done, reflectance was calculated by

$$
R=1-(A+T)
$$

the $\mathrm{B}$ and $\mathrm{Q}$ bands have high variations in $\mathrm{R}$ while the flat area has still minimum variations. At $450 \mathrm{~K}$ substrate temperature $\mathrm{R}$ takes the same values for wide range and for both bands. The reflectance spectra for NiPc film at various $\mathrm{T}_{\mathrm{s}}$ were given in Figure 3 and Table 1.

Substrate temperature variations effect on reflectance of NiPc thin films, where reflectance increases by increase in $\mathrm{T}_{\mathrm{s}}$ for $\mathrm{B}$ and $\mathrm{Q}$ bands except for the range of $T_{s}(350-400) \mathrm{K}$. The reflectance of flat also plotted with $T_{s}$ it seems to be that it behaves inversely. The effect of $\mathrm{T}_{\mathrm{s}}$ on reflectance was given in Figure 4 . The behaviour in Figure 4 may be due to recrystalization by increasing temperature and phase transition from $\beta$-phase to $\alpha$-phase [15] [16].

Figure 5 represents the variations in absorption coefficient $(\alpha)$ with wavelengths at various temperatures, the following equation gives $\alpha$ :

$$
\alpha=(2.303) A \cdot t^{-1}
$$

Absorption represents by $(A)$, and $(t)$ thickness, it is observed the flat area at the range (400 - 500) $\mathrm{nm}$ having the same values of absorption coefficient approximately, because this range is the high transmission range; while for $\mathrm{B}$ band, absorption coefficient becomes greater than $10^{4} \mathrm{~cm}^{-1}$ which means high proba- 
bility for direct transition. The high absorption coefficient in Q band is due to traps inside energy gap.

Effect of $T_{s}$ for NiPc film was given in Figure 6, absorption coefficient decreases with substrate temperature increases, normally, except in the range (350 - 400) $\mathrm{nm}$ a reverse behaviour has been seen that is due to enhancement in crystal structure.

The absorption coefficient $(\alpha)$, and types of transition can be deduced from Tauc relation [14]:

$$
\alpha h v=\text { const. }(h v-E g)^{r}
$$

where $r$ is empirical constant depending on the transition types, where $r$ is equal to $1 / 2$ for allowed direct transition, and $h v$ represent photon energy which equals to [13] [14]:

$$
h v(\mathrm{eV})=1.24 \cdot \lambda^{-1}(\mu \mathrm{m})
$$

Plank constant was $h, v$ is frequency, $\lambda$ represents wavelength. By polting $(\alpha h v)^{2}$ against $h v$ for allowed direct transition, and the absorption coefficient $\alpha \geq$ $10^{4} \mathrm{~m}^{-1}$, the straight line indicating the transition is allowed direct. Extrapolation of the linear portion of the plot to the $x$ axis $(\alpha h v=0)$ represent the values of energy gap as shown in Figure 7 [15] [16].

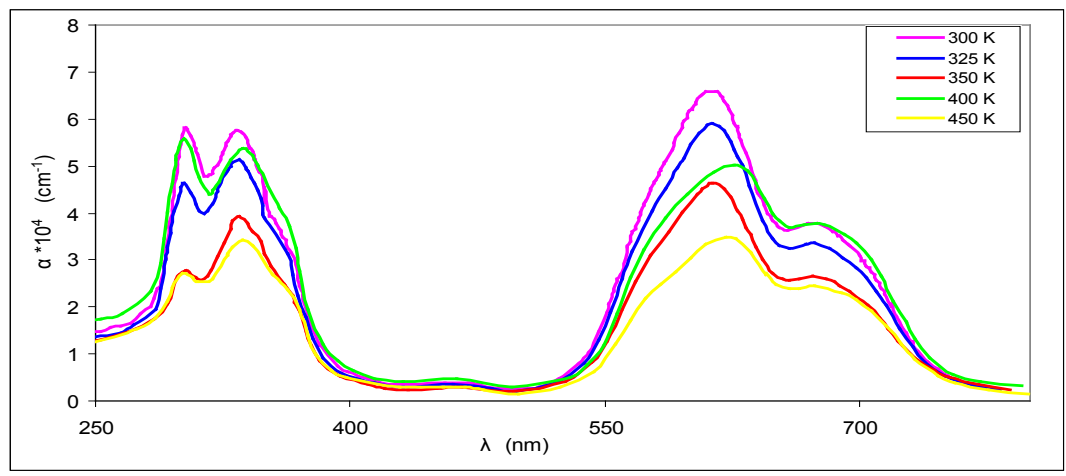

Figure 5. $\alpha$ versus $\lambda$ for NiPc films at various $\mathrm{T}_{\mathrm{s}}$.

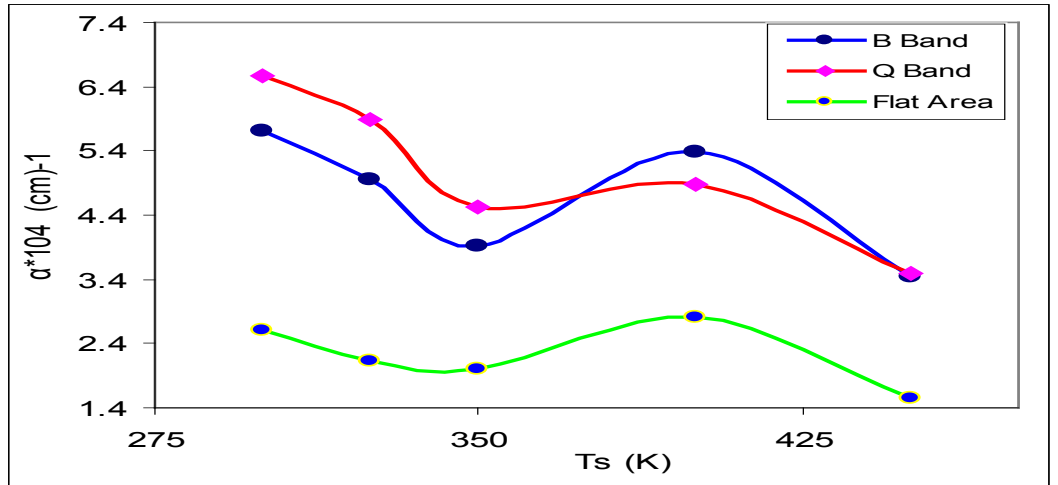

Figure 6. Substrate temperature effect of NiPc thin film on absorption coefficient for $\mathrm{B}$ and $\mathrm{Q}$ bands. 


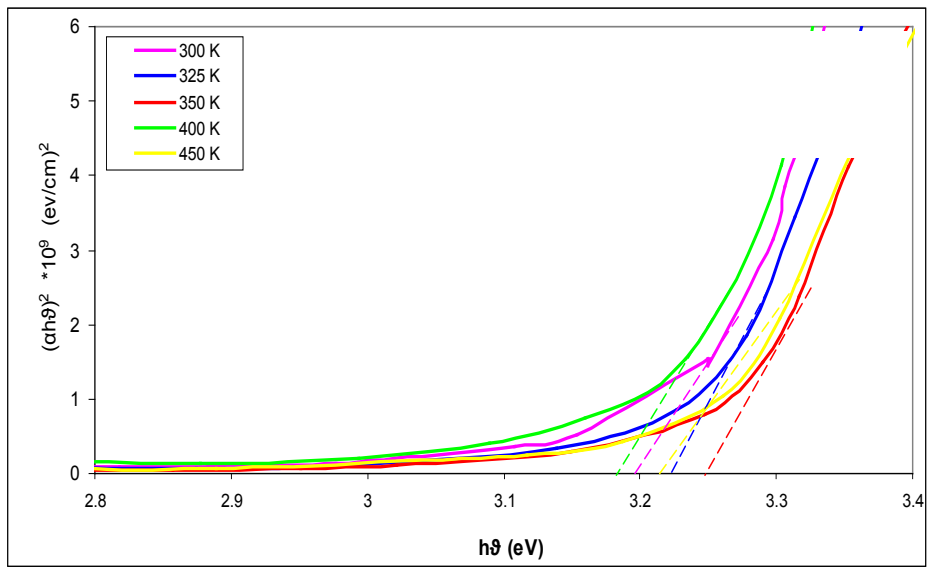

Figure 7. $(\alpha h v)^{2}$ vs $h v$ for Nickel phthalocyanine film at various $\mathrm{T}_{\mathrm{s}}$.

Values of Eg increases with increasing substrate temperature slightly as given in Table 2. This is due to the decrease of defects and improvement in crystal structure of thin prepared films [15] [16].

The optical constants for NiPc thin films at wavelength equal to $500 \mathrm{~nm}$ at different substrate temperatures were shown in Table 3.

The refractive index (n) can be evaluated from equations [13] [14].

$$
n=\left[\left(4 R /(R-1)^{2}\right)-k^{2}\right]^{1 / 2}-(R+1) /(R-1)
$$

where $(R)$ is the reflectance. The extinction coefficient $(k)$ is calculated from [13] [14].

$$
k=\alpha \lambda / 4 \pi
$$

The dielectric constant is:

$$
\varepsilon=\varepsilon_{1}-i \varepsilon_{2}=1+4 \pi \varphi
$$

$(\varphi)$ is the sum of polarizabilities resulting from free carries. So that [14]

$$
\begin{gathered}
\varepsilon_{1}=n^{2}-k^{2} \\
\varepsilon_{2}=2 n k
\end{gathered}
$$

Photoluminese spectra have an important role because they give information about the optical properties, likes Eg, excitons, traps and levels of energy. The $\mathrm{E}_{\mathrm{g}}$ which calculated from photoluminese spectra $(\mathrm{pL})$ is more precision from Tauc equation. Figure 8 represents (pL) spectra for Nickel phthalocyanine film at various $\mathrm{T}_{\mathrm{s}}$, Table 4 gives energy gap obtained by PL spectra and by Tauc method at different substrate temperatures with excitation wavelength $315 \mathrm{~nm}$. The lowest value for $E_{g}$ is at $T_{s} 400 \mathrm{~K}$, it is the same result found by Tauc equation. All $\mathrm{E}_{\mathrm{g}}$ values found by PL spectra are greater than that found by Tauc equation method for all studied range of substrate temperatures. Traps in energy gap take part in an important role in organic material conductivity, to study the behavior of traps inside energy gap, two photoluminescence spectra were recorded for NiPc thin films at $110 \mathrm{~nm}$ thickness, one using excitation wavelengths $315 \mathrm{~nm}$ (where 
photons energy greater than $\mathrm{E}_{\mathrm{g}}$ ), and the other about half of energy gap (600 $\mathrm{nm})$. Photoluminescence spectra for two excitation wavelengths are shown in Figure 9. It shows the ordinary behavior when NiPc excited by a photon with energy $3.93 \mathrm{eV}$ (excitation wavelength $315 \mathrm{~nm}$ ) which gives emitting photon with $3.29 \mathrm{eV}$ (wavelength $376 \mathrm{~nm}$ ). The small peak gives emitting photons with 3 $\mathrm{eV}$ which is the Eg approximately. An extra ordinary behavior also happened when NiPc thin film excited by a photon with energy $2.06 \mathrm{eV}$ (wavelength 600 $\mathrm{nm}$ ) and gives emitting photon with energy $3.6 \mathrm{eV}$ (wavelength $344 \mathrm{~nm}$ ). The abnormal behavior may refer to nonlinear properties. Photoluminescence spectra for NiPc thin films at thicknesses (110) nm were done using exciting wavelength $600 \mathrm{~nm}$ as shown in Figure 10. We can see both of two thin films give emitting photon energy about $3.6 \mathrm{eV}$ (wavelength $344 \mathrm{~nm}$ ). As a result the traps which represented by $\mathrm{Q}$ band has great importance in conductivity of $\mathrm{NiPc}$ film [15] [16].

Table 2. Substrate temperature effect on Eg and traps for Nickel phthalocyanine film.

\begin{tabular}{cccc}
\hline Ts & Eg & Trap (1) & Trap (2) \\
$(\mathrm{K})$ & $(\mathrm{eV})$ & Energy $(\mathrm{eV})$ & 1.84 \\
\hline 300 & 3.21 & 2.01 & 1.84 \\
325 & 3.23 & 2 & 1.84 \\
350 & 3.27 & 2 & 1.84 \\
400 & 3.19 & 1.98 & 1.84 \\
450 & 3.25 & 1.98 & \\
\hline
\end{tabular}

Table 3. The optical constants for NiPc films with different substrate temperature at $\lambda=$ $500 \mathrm{~nm}$.

\begin{tabular}{cccccc}
\hline$T_{s}(K)$ & $\boldsymbol{a} \times 10^{4}(\mathrm{~cm})^{-1}$ & $\boldsymbol{n}$ & $K^{*} 10^{-4}$ & $\varepsilon_{\boldsymbol{r}}$ & $\varepsilon_{i}$ \\
\hline 300 & 2.614 & 1.2295 & 105 & 1.511 & 0.025 \\
325 & 2.126 & 1.187 & 84 & 1.41 & 0.02 \\
350 & 2 & 1.176 & 79 & 1.384 & 0.018 \\
400 & 2.806 & 1.246 & 11 & 1.552 & 0.027 \\
450 & 1.539 & 1.136 & 61 & 1.291 & $\mathbf{0 . 0 1 3 9}$ \\
\hline
\end{tabular}

Table 4. Energy gap obtained by photoluminescence and Tauc method at different substrate temperatures excitation wavelength $315 \mathrm{~nm}$.

\begin{tabular}{cccc}
\hline $\mathrm{T}_{\mathrm{s}}(\mathrm{K})$ & $E_{g}(P L)(\mathrm{eV})$ & $E_{g}(\mathrm{Tauc})(\mathrm{eV})$ & Error ratio\% \\
\hline 300 & 3.27 & 3.21 & 1.5 \\
325 & 3.29 & 3.23 & 1.8 \\
350 & 3.29 & 3.27 & 0.6 \\
400 & 3.26 & 3.19 & 2.1 \\
450 & 3.28 & 3.25 & 0.9 \\
\hline
\end{tabular}




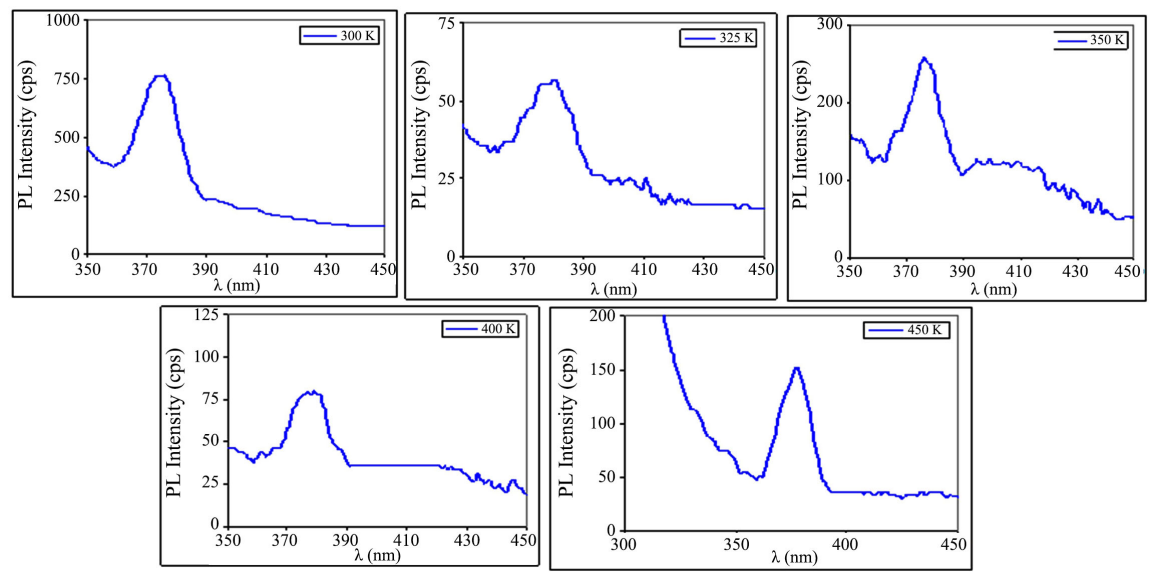

Figure 8. Photoluminescence spectra for Nickel phthalocyanine film at various Ts using excitation wavelength $315 \mathrm{~nm}$.

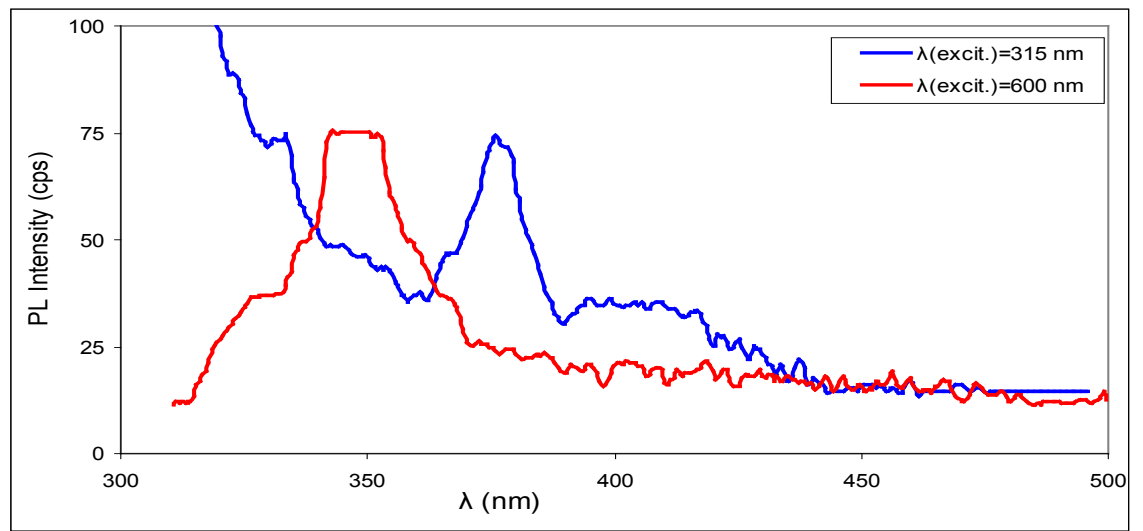

Figure 9. Photoluminescence spectra for NiPc thin films at thickness $110 \mathrm{~nm}$ using excitation wavelengths (315 and $600 \mathrm{~nm}$ ).

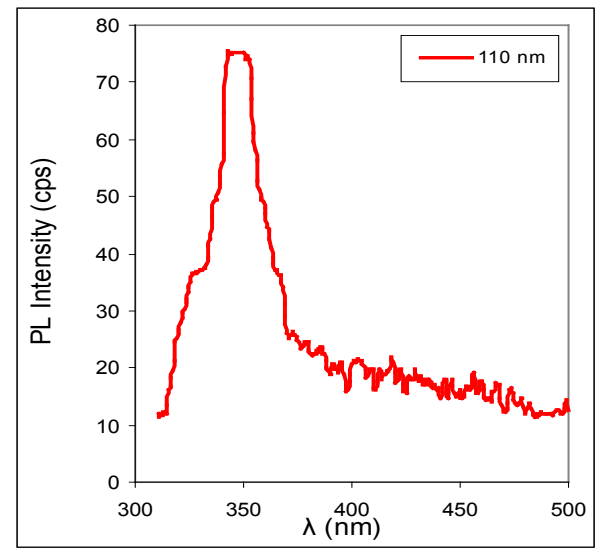

Figure 10. Photoluminescence spectra for NiPc thin films at thicknesses (110) nm using excitation wavelength $600 \mathrm{~nm}$.

The D.C. conductivity for NiPc thin films was calculated as listed in Table 5, the room temperature conductivity increase as film Ts increases for the (325 450) $\mathrm{K}$ about five times and this is attributed to better crystallinity (grain size). 
By plotting Ln $\sigma$ versus of $10^{3} / \mathrm{T}$ as shown in Figure 11, activation energy $\left(\mathrm{E}_{\mathrm{a}}\right)$ can be determined. The electronic transport mechanism is influenced by the intergrain boundaries. As it is observed from Figure 11, there are three activation energies within the range $(298-473) \mathrm{K}$ as in Figure 11 and Table 5 and this conformed by [17] [18].

As shown in Figure 12, the activation energy $\left(E_{a}\right)$ values vary with $T_{s}$ due to variations crystalline structure of the prepared film [17].

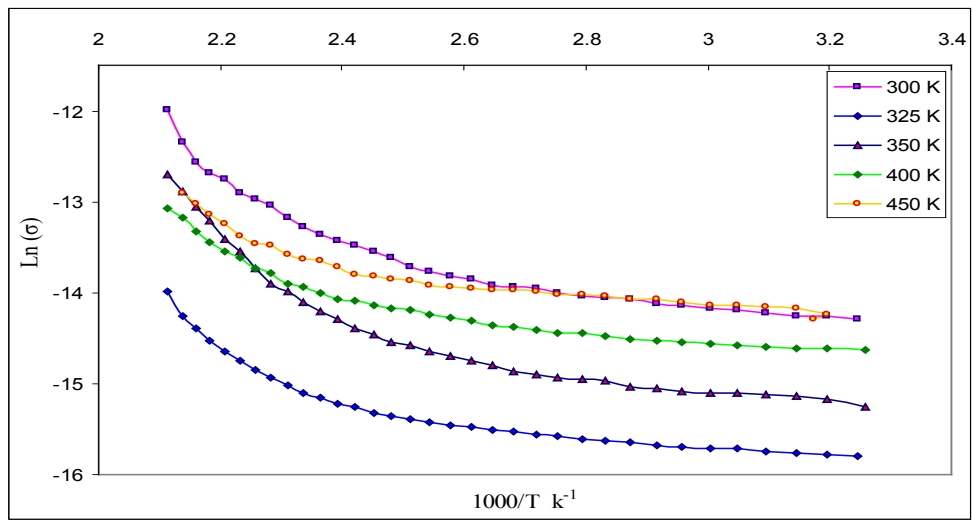

Figure 11. Ln $\sigma$ versus of $10^{3} / \mathrm{T}$ to film of NiPc for various Ts.

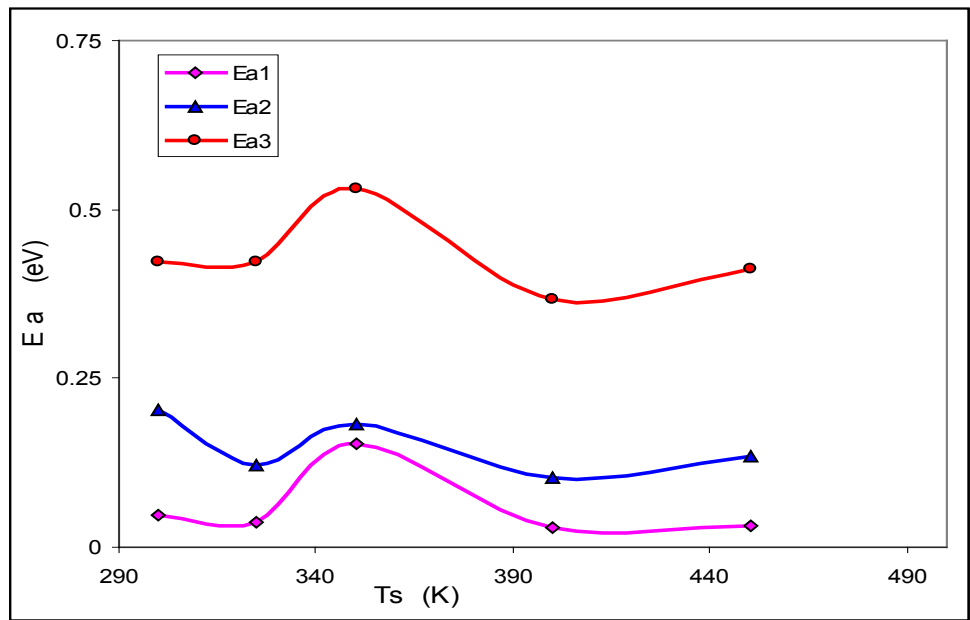

Figure 12. Effect of $\mathrm{T}_{\mathrm{s}}$ on $\mathrm{E}_{\mathrm{a}}$ for Nickel-Pc films.

Table 5. The electrical parameters: Ea, and $\sigma_{\mathrm{R} . \mathrm{T}}$ for Nickil phthalocyanine film for various Ts.

\begin{tabular}{cccccccc}
\hline Ts $(\mathrm{K})$ & $\begin{array}{c}\sigma_{\mathrm{R} . \mathrm{T}} \times 10^{-7} \\
(\boldsymbol{\Omega} . \mathrm{cm})^{-1}\end{array}$ & $\begin{array}{c}\mathrm{E}_{\mathrm{a} 1} \\
(\mathrm{eV})\end{array}$ & $\begin{array}{c}\text { Temp. Range } \\
(\mathrm{K})\end{array}$ & $\begin{array}{c}\mathrm{E}_{\mathrm{a} 2} \\
(\mathrm{eV})\end{array}$ & $\begin{array}{c}\text { Temp. Range } \\
(\mathrm{K})\end{array}$ & $\begin{array}{c}\mathrm{E}_{\mathrm{a} 3} \\
(\mathrm{eV})\end{array}$ & $\begin{array}{c}\text { Temp. Range } \\
(\mathrm{K})\end{array}$ \\
\hline 300 & 6.22 & 0.0478 & $308-378$ & 0.2044 & $393-433$ & 0.4223 & $433-468$ \\
325 & 1.377 & 0.037 & $308-336$ & 0.121 & $388-428$ & 0.423 & $438-468$ \\
350 & 2.382 & 0.182 & $307-368$ & 0.182 & $372-423$ & 0.53 & $428-473$ \\
400 & 4.459 & 0.03 & $307-358$ & 0.104 & $373-423$ & 0.368 & $433-473$ \\
450 & 6.807 & 0.033 & $307-393$ & 0.135 & $393-443$ & 0.411 & $443-473$ \\
\hline
\end{tabular}


Carrier concentration (n) can be calculated which decreases from (10 - 0.302) $\mathrm{cm}^{-3}$ for Ts (325 - 450) $\mathrm{K}$ except at $300 \mathrm{~K}$, and P-types films have been observed by Hall effects, whereas the carriers mobility $(\mu)$ up from $0.03\left(\mathrm{~cm}^{2} / \mathrm{v} . s\right.$. $)$ to 99.42 $\left(\mathrm{cm}^{2} /\right.$ v.s. $)$ by increasing $\mathrm{T}_{\mathrm{s}}$ from $(325-450) \mathrm{K}$ for prepared films except at $300 \mathrm{~K}$, and this is given in Table 6. From the Table the carrier mobility increases with substrate temperature except at $300 \mathrm{~K}$ while the carrier concentration decreases with increases of substrate temperature [17] [18].

$\mathrm{p}-\mathrm{NiPc} / \mathrm{n}-\mathrm{Si}$ solar cells have been fabricated thermally by deposited the organic material NiPc on n-type silicon wafer, at substrate temperatures of $(300,400)$ $\mathrm{K}$ with $265 \mathrm{~nm}$ thickness. The characteristic of Capacitance (C)-Voltage (V) have been described at RT for P-NiPc/n-Si HJ at substrate temperatures of (300, 400) K. It is observed from Figure 13. By increasing of bias voltage the values of $\mathrm{C}$ are decreases, due to the higher values of depletion width (W) leading to increase of built-in voltage $\left(\mathrm{V}_{\mathrm{bi}}\right)$. By plotting $\mathrm{C}^{-2}$ with reverse voltage bias (Figure 14) the intersection $C^{-2}=0$ represent $V_{b i}$. It is observed from this figure increase in built-in potential with high temperatures, Reason for this is improvement in structural defects and the progress films during deposition (i.e. grain boundaries, stacking faults), as shown in Table 7.
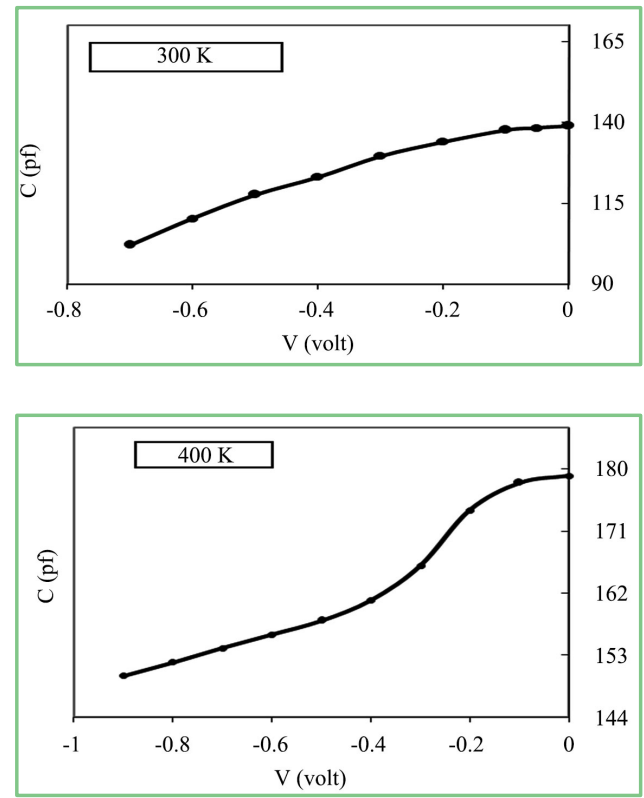

Figure 13. The capacitance of $\mathrm{NiPc} / \mathrm{Si} \mathrm{HJ}$ versus reverse bias voltage, for Ts $(300,400) \mathrm{K}$.

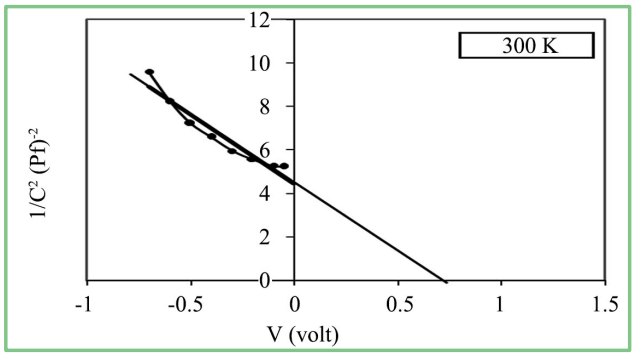




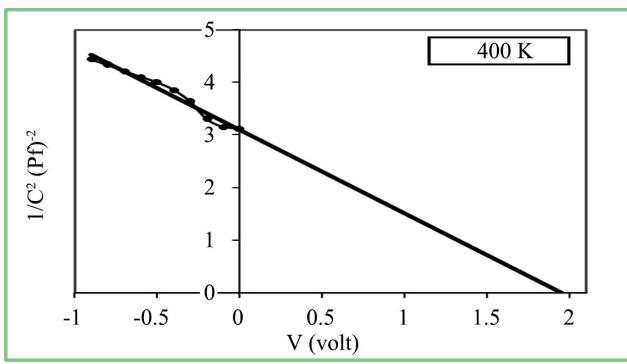

Figure 14. The variation of the inverse capacitance squared for $\mathrm{NiPc} / \mathrm{Si} \mathrm{HJ}$ with the reverse bias voltage for Ts $(300,400) \mathrm{K}$.

Table 6. $\mathrm{n}$ and $\mu$ for NiPc film at various Ts.

\begin{tabular}{ccc}
\hline $\mathrm{T}_{s}(\mathrm{~K})$ & $\mathrm{n}^{*} 10^{12}\left(\mathrm{~cm}^{-3}\right)$ & $\mu\left(\mathrm{cm}^{2} / \mathrm{v} . \mathrm{s}.\right)$ \\
\hline 300 & 0.396 & 72.74 \\
325 & 10.8 & 0.030 \\
350 & 2.75 & 8.922 \\
400 & 0.480 & 73.4 \\
450 & 0.302 & 99.42 \\
\hline
\end{tabular}

Table 7. The capacitance at zero bias voltage $\mathrm{C}_{\mathrm{o}}$, and built-in potential $\mathrm{V}_{\mathrm{bi}}$ for the p-NiPc/n-Si.

\begin{tabular}{cccc}
\hline Thickness $(\mathrm{nm})$ & $T s$ & $C_{o}$ & $\mathrm{~V}_{\mathrm{bi}}$ \\
& $(K)$ & $(p f)$ & $($ Volt $)$ \\
\hline 265 & 300 & 140 & 0.69 \\
265 & 400 & 180 & 1.7 \\
\hline
\end{tabular}

Figure 15 represents the current-voltage characterization for NiPc-Silicon HJ for both biases in the dark at substrate temperatures of $(300,400) \mathrm{K}$. These curves showed the conduct of the current at two bias of voltage. From Figure 15, two regions have been observed at forward current. From $(0-0.2 \mathrm{~V})$ for recombination current, and from $0.2 \mathrm{~V}$ to $0.4 \mathrm{~V}$ represents the tunneling current. Also the current at reverse bias voltage contains two regions for generation and diffusion process.

Figure 16 gives the semi logarithmic plot of the current-voltage Curve, the initial part voltage range $(0-0.2)$ Volt could be approximated by an expression of the type $\mathrm{I} \sim \exp \left(\mathrm{qV} / \beta \mathrm{k}_{\mathrm{B}} \mathrm{T}\right)$. So the ideality factor $\beta$ has been calculated and it is about $0.613-0.734$ which indicate on the mechanism of conduction is generation and diffusion.

The series resistance $\left(R_{s}\right)$ and shunt resistance $\left(R_{s h}\right)$ of the junction can be evaluated by plotting resistance of junction $\left(\mathrm{R}_{\mathrm{j}}\right)$ versus applied voltage as in Figure 17 and Table 8 gives these parameters of two NiPc/Si HJ samples.

The main factor for working of solar cell is photocurrent (Iph). The photocurrent for $\mathrm{NiPc} / \mathrm{Si} \mathrm{HJ}$ at substrate temperatures of $(300,400) \mathrm{K}$ were plotted against reveres and forward bias as shown in Figure $18, V_{o c}, I_{s c}$ were determined 
by the intersect of photocurrent curve with $\mathrm{x}$ and $\mathrm{y}$ axis. Also maximum voltage $\left(\mathrm{V}_{\mathrm{m}}\right)$ and current $\left(\mathrm{I}_{\mathrm{m}}\right)$ for solar cell were found, full factor (F.F) and efficiency $(\eta)$ have been calculated. For HJ under illumination, the photocurrent increases with increasing of voltage which leads to separate electrons and holes and then increases the photocurrent to higher values. The light current depends on the processes of generation and diffusion. The results comparison tabulated in $\mathrm{Ta}$ ble 9 leads to that the selected thickness and substrate temperatures are a good choice, where the results of photocurrent parameters increase with increasing substrata temperatures.

Table 8. The values of $\beta$, Is, $\varphi_{b}, R_{s h}$ and $\mathrm{R}_{s}$ for substrate temperatures of $(300,400) \mathrm{K}$.

\begin{tabular}{cccccc}
\hline $\mathrm{T}(\mathrm{K})$ & $\beta$ & $I_{s}(\mu A)$ & $\varphi_{b}(V)$ & $R_{s h}(K \Omega)$ & $\mathrm{R}_{s}(\mathrm{~K} \Omega)$ \\
\hline 300 & 0.61 & 0.54 & 2.53 & 3.76 & 0.24 \\
400 & 0.734 & 0.23 & 3.69 & 2.58 & 0.23 \\
\hline
\end{tabular}

Table 9. The values of $\mathrm{V}_{\mathrm{oc}}, \mathrm{I}_{\mathrm{sc}}, \mathrm{V}_{\mathrm{m}}, \mathrm{I}_{\mathrm{m}}, \mathrm{J}, \mathrm{P}_{\mathrm{Max}}, \mathrm{F} . \mathrm{F}$ and $\eta$ for substrate temperatures of (300, 400) K.

\begin{tabular}{ccccccccc}
\hline $\begin{array}{c}\text { Sample } \\
\text { no. }\end{array}$ & $\begin{array}{c}\text { Voc } \\
(\mathrm{V})\end{array}$ & $\begin{array}{c}I_{s c} \\
(\mathrm{~mA})\end{array}$ & $\begin{array}{c}V_{m} \\
(\mathrm{~V})\end{array}$ & $\begin{array}{c}I_{m} \\
(\mathrm{~mA})\end{array}$ & $\begin{array}{c}J \\
\left(\mathrm{~mA} . \mathrm{cm}^{-2}\right)\end{array}$ & $\begin{array}{c}\mathrm{P}_{\text {Max }} \\
(\text { miliwatt })\end{array}$ & $F . F$ & $\begin{array}{c}\eta \\
\%\end{array}$ \\
\hline 1 & 0.335 & 2.77 & 0.24 & 1.77 & 11.08 & 0.4248 & 0.457 & 3.08 \\
2 & 0.415 & 4.26 & 0.25 & 2.77 & 17.04 & 0.6925 & 0.391 & 5.03 \\
\hline
\end{tabular}
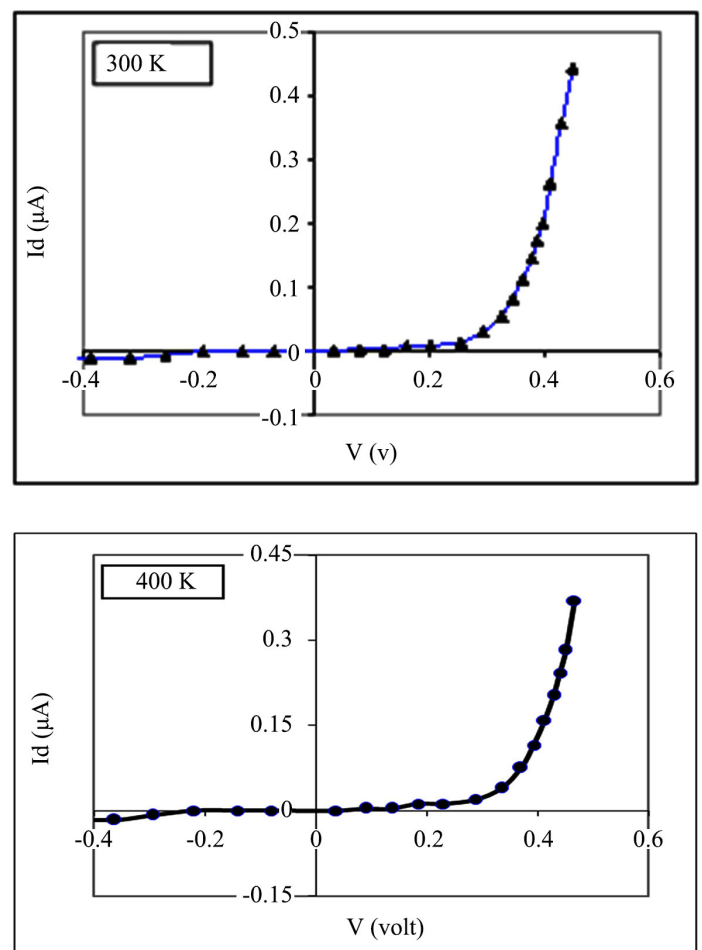

Figure 15. I-V characteristics for NiPc-Silicon $\mathrm{HJ}$ for $\mathrm{T}_{\mathrm{s}}(300$, 400) $\mathrm{K}$ in case of darkness at forward bias and reverse bias. 

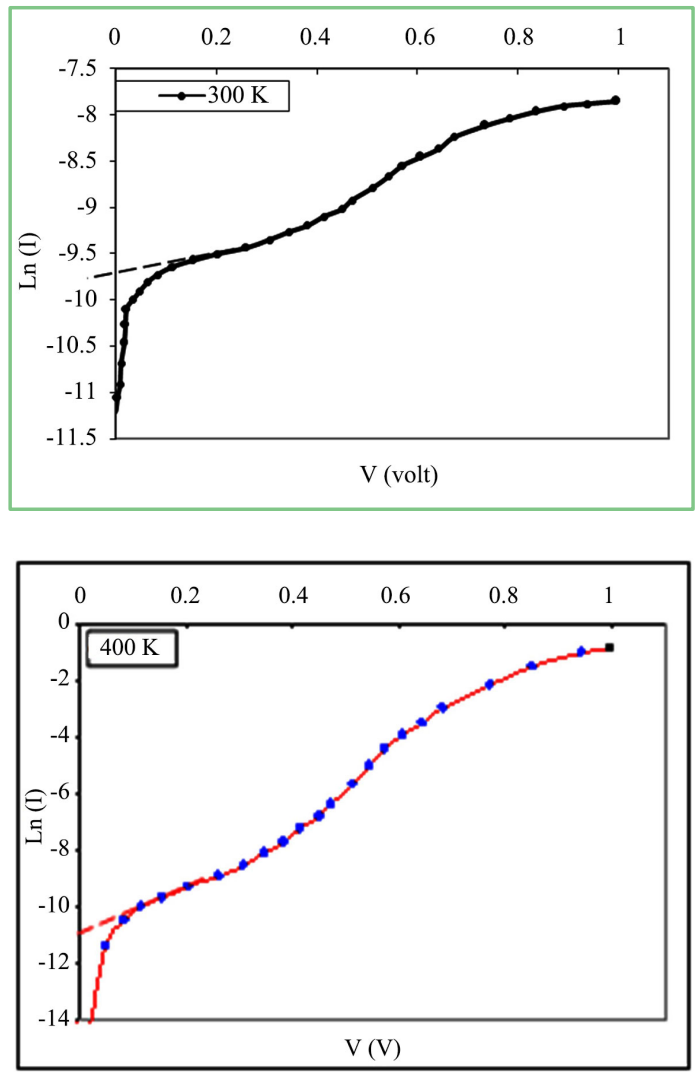

Figure 16. Semi logarithmic plot of the I-V characteristics for NiPc-Silicon $\mathrm{HJ}$ at forward bias voltage for $\mathrm{T}_{s}(300,400) \mathrm{K}$ in case of darkness.
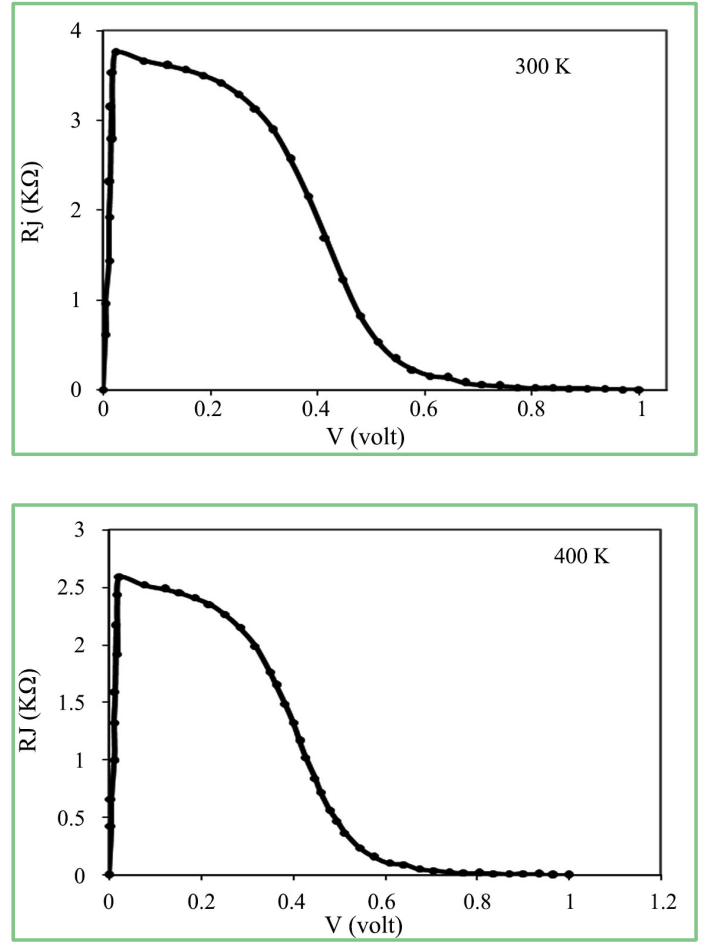

Figure 17. The junction resistance with the external applied voltage for substrate temperatures of $(300,400) \mathrm{K}$. 

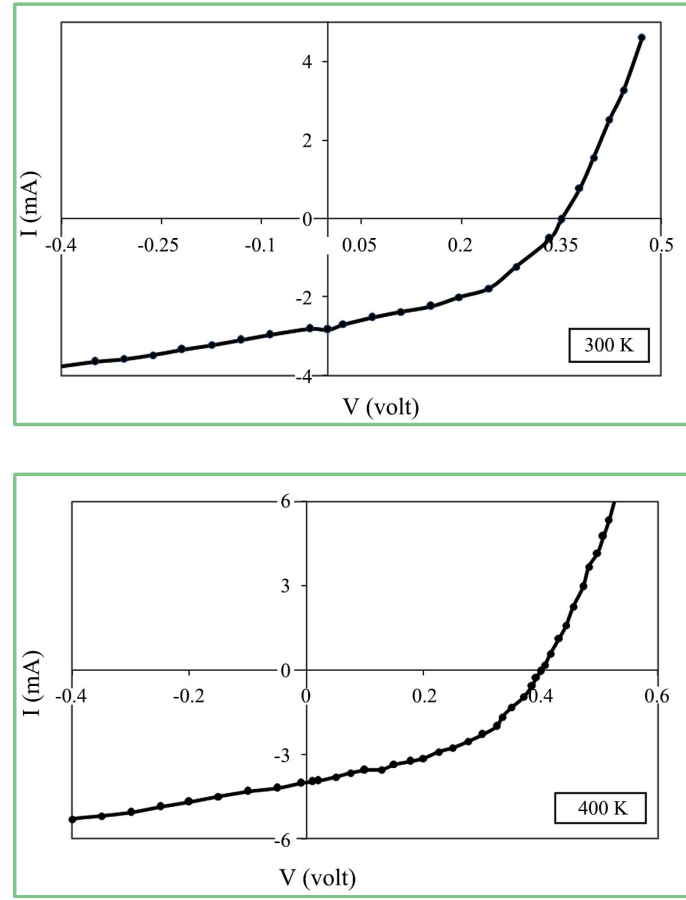

Figure 18. The photocurrent for NiPc/Si HJ for substrate temperatures of $(300,400) \mathrm{K}$.

\section{Conclusions}

Thermally evaporated $\mathrm{Ni}-\mathrm{Pc}$ film with various substrate temperatures was prepared excellently. It was found that all $\mathrm{E}_{\mathrm{g}}$ values found by PL spectra are greater than those found by Tauc equation method for all studied range of substrate temperatures. Fluorescence spectra confirmed the splitting of soret band. The energy gap values are increased by raising the base temperature. There are three activation energies increasing with the increase of substrate temperatures. P-types films have been observed by Hall effects. Carrier concentration and mobility have been reduced by increasing of substrate temperatures. Results of photocurrent parameters increase with increasing substrate temperatures. The maximum efficiency was obtained around $5 \%$ at thickness of $265 \mathrm{~nm}$ and $400 \mathrm{~K}$. The results indicate that the selected thickness and substrate temperatures are a good choice for solar cell applications.

\section{Conflicts of Interest}

The authors declare no conflicts of interest regarding the publication of this paper.

\section{References}

[1] El-Nahass, M.M., Bahabri, F.S. and Al-Harbi, S.R. (2001) Optical Properties of Copper Phthalocyanine (CuPc) Thin Films. Egyptian Journal of Solids, 24, 307-311.

[2] Yanagi, H., Kouzeki, T. and Ashda, M. (1992) Molecular Orientation of Vacuum-Deposited Thin Films of Zinc Naphthalocyanine. Journal of Applied Physics, 
71, 5146-5153. https://doi.org/10.1063/1.350569

[3] Burgess, A.N. (1987) Comparison of Transient Thermal Conduction in Tellurium and Organic Dye Based Digital Optical Storage Media. Journal of Applied Physics, 61, 74. https://doi.org/10.2307/40142489

[4] Dini, D., Barthel, M. and Hanack, M. (2001) Phthalocyanines as Active Materials for Optical Limiting. European Journal of Organic Chemistry, 9, 3759-3769. https://doi.org/10.1002/1099-0690(200110)2001:20<3759::AID-EJOC3759>3.0.CO;2 $\underline{-\mathrm{U}}$

[5] Liu, Z.T., Kwok, H.S. and Djurisic, A.B. (2004) The Optical Functions of Metal Phthalocyanines. Journal of Physics D: Applied Physics, 37, 678. https://doi.org/10.1088/0022-3727/37/5/006

[6] Kumar, G.A., Jose, G., Thomas, V., Unnikrishnan, N.V. and Nampoori, V.P.N. (2003) NIR to UV Absorption Spectra and the Optical Constants of Phthalocyanines in Glassy Medium. Spectrochimica Acta Part, 59, 1-11. https://doi.org/10.1016/S1386-1425(02)00037-9

[7] Raji, P., Sanjeeviraja, C. and Ramachandran, K. (2005) Thermal and Structural Properties of Spray Pyrolysed CdS Thin Film. Bulletin of Materials Science, 28, 233-238. https://doi.org/10.1007/BF02711253

[8] Hendi, A.A. (2011) Determination and Analysis the Influence of X-Ray Irradiation on Optical Constant of Magnesium Phthalocyanin. Australian Journal of Basic and Applied Sciences, 5, 38-44.

[9] Hussein, M.T., Nasir, E.M. and Al-Aarajiy, A.H. (2013) Structural and Surface Morphology Analysis of Nickel Phthalocyanine Thin Films. Advances in Materials Physics and Chemistry, 3, 113-119. https://doi.org/10.4236/ampc.2013.31A014

[10] Joseph, B. and Menon, C.S. (2007) Studies on the Optical Properties and Surface Morphology of Nickel Phthalocyanine Thin Films. E-Journal of Chemistry, 4, 255-264. https://doi.org/10.1155/2007/643834

[11] Pustelny, T., Ignac, J., Jarzabek, B. and Burian, A. (2004) Optical Investigation Concerning Layered Metal Phthalocyanine Nanostructures Affected by $\mathrm{NO}_{2}$. Optica Applicata, 34, 551-561.

[12] Hummel, R.E. (2001) Electronic Properties of Materials. 3rd Edition, Springer, New York.

[13] Schroder, D. (1990) Semiconductor Material and Device Characterization. John Wiley \& Sons, Hoboken.

[14] Pankove, J.L. (1971) Optical Processes in Semiconductors. Prentice-Hall, Englewood Cliffs.

[15] Hussein, M.T., Nasir, E.M. and Al-Aarajiy, A.H. (2012) Study on the UV-Visible of Ni-Phthalocyanine Thin Film Optical Properties. International Journal of Thin Films Science and Technology, 1, 71-76.

[16] Hussein, M.T., Eman, M.N. and Senaed, F.A. (2014) Optical Properties of Cobalt Phthalocyanine Thin Films. Indian Journal of Research, 3, 145-147.

[17] Hussein, M.T., Eman, M.N., Thekra, K. and Senaed, F.A. (2014) Study the Effect of Annealing Temperature on the Structural, Morphology and Electrical Properties CoPc Thin Films. International Journal of Current Engineering and Technology, 4, 3263-3269.

[18] Nasir, E.M., Hussein, M.T. and Al-Aarajiy, A.H. (2019) Impact Thickness on Structural and Electrical Characterization of Nickel Phthalocyanine Thin Films. Advances in Materials Physics and Chemistry, 9, 123-132. https://doi.org/10.4236/ampc.2019.97010 